\title{
Nutrition and immunity: lessons for COVID-19
}

\author{
Philip C. Calder $\mathbb{1}^{1,2}$
}

Received: 8 April 2021 / Revised: 6 May 2021 / Accepted: 17 May 2021 / Published online: 23 June 2021

(c) The Author(s) 2021. This article is published with open access

\begin{abstract}
The role of the immune system is to protect the individual against pathogenic organisms. Nutrition is one of multiple factors that determines the immune response and good nutrition is important in supporting the immune response. Immunity can be impaired in older people, particularly those who are frail, in those living with obesity, in those who are malnourished and in those with low intakes of micronutrients. The immune impairments associated with nutritional inadequacy increase susceptibility to infection and permit infections to become more severe, even fatal. The adverse impact of poor nutrition on the immune system, including its inflammatory component, may be one of the explanations for the higher risk of more severe outcomes from infection with SARS-CoV-2 seen in older people and in those living with obesity. Studies of individual micronutrients including vitamin D and zinc suggest roles in reducing severity of infection with SARS-CoV-2. Good nutrition is also important in promoting a diverse gut microbiota, which in turn supports the immune system. The importance of nutrition in supporting the immune response also applies to assuring robust responses to vaccination. There are many lessons from the study of nutrition and immunity that are relevant for the battle with SARS-CoV-2.
\end{abstract}

\section{Introduction and scope}

Coronaviruses are a large group of single-stranded RNA viruses that cause respiratory and, less frequently, gastrointestinal diseases. The respiratory symptoms caused by coronaviruses range from common cold-like or mild influenza-like symptoms to severe pneumonia. In December 2019, a new coronavirus causing pneumonia and death was identified in Wuhan, China; this new coronavirus is called severe acute respiratory distress syndrome coronavirus (SARS-CoV) 2 (SARS-CoV-2) because it is genetically similar to SARS-CoV which caused an outbreak of severe acute respiratory distress syndrome in 2002. Although

This article is co-published in the journals European Journal of Clinical Nutrition and Nutrition \& Diabetes https://doi.org/10.1038/ s41430-021-00949-8 or https://doi.org/10.1038/s41387-021-00165-0

Philip C. Calder

pcc@soton.ac.uk

1 School of Human Development and Health, Faculty of Medicine, University of Southampton, Southampton, UK

2 NIHR Southampton Biomedical Research Centre, University Hospital Southampton NHS Foundation Trust and University of Southampton, Southampton, UK
SARS-CoV-2 is the seventh known human coronavirus, it is new to the human immune system and so there was no underlying existing immunity against it, explaining why SARS-CoV-2 spread so rapidly and has caused such severe illness; this illness is called coronavirus disease discovered in 2019 or COVID-19. The extent of the health, societal and economic consequences that have arisen due to the presence of SARS-CoV-2 and the severity of COVID-19 have focussed attention on the devastation infectious illness can cause and on the importance of having well-functioning immune systems. Inadequate immune responses have been exposed as a major public health liability in settings where this was previously either not well recognised or simply accepted. Vaccines work by training the immune system to work properly against a pathogen. The apparent effectiveness of the newly-developed vaccines to protect against COVID-19 is evidence of the inherent weakness of the immune system amongst significant subgroups in the population; nevertheless vaccinations themselves require a robust immune response to work properly and there has been some debate about the usefulness of some of the vaccines amongst those groups of the population who may have weakened immune responses. It is also likely that new vaccines will be developed in the future, especially with emergence of new variants of SARS-CoV-2. In the meantime, alongside the existing vaccination programmes, the 


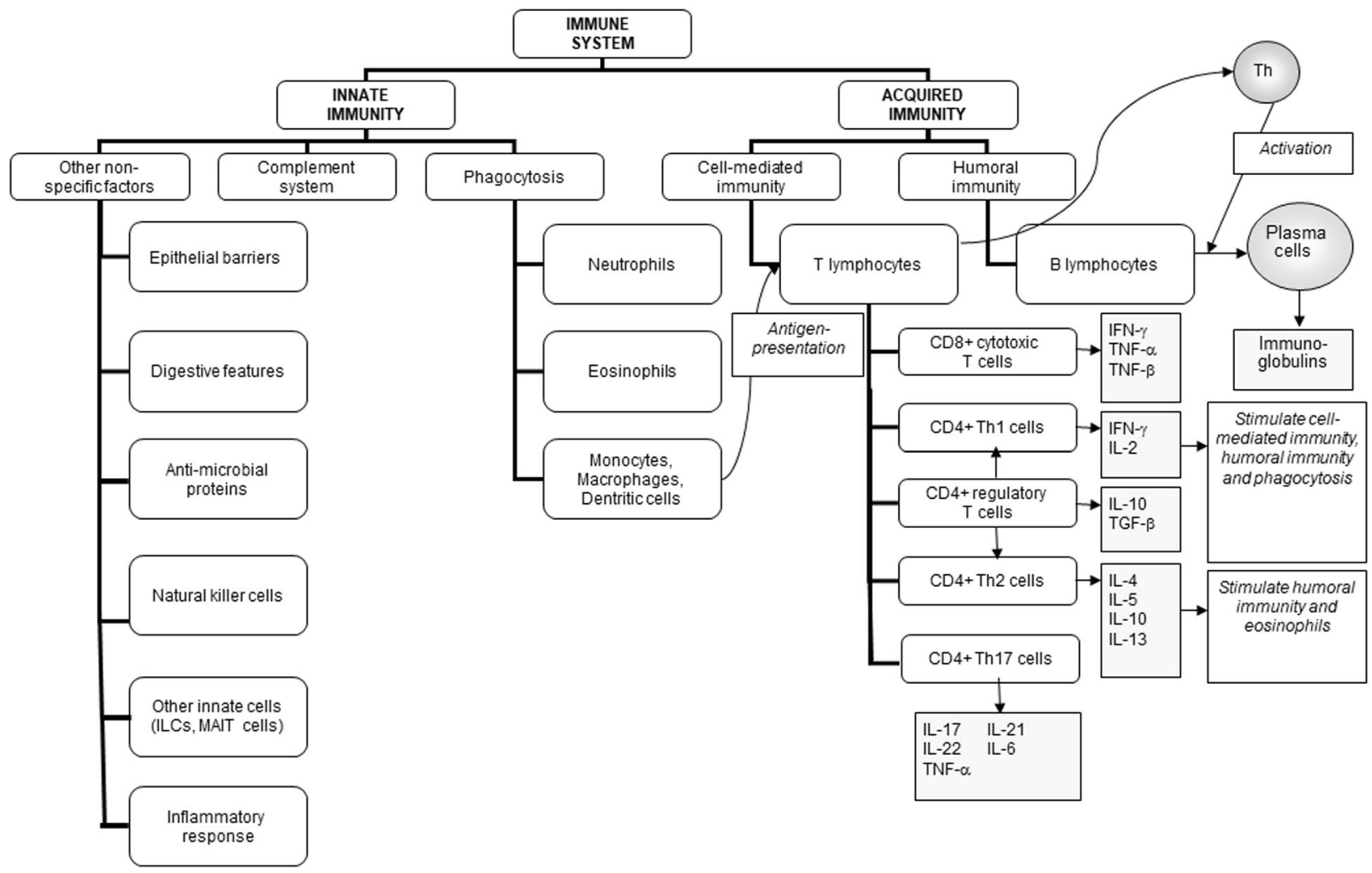

Fig. 1 The components of the immune system and their division into innate and acquired immunity. IFN interferon, IL interleukin, ILCs innate lymphoid cells, MAIT mucosal associated invariant T, TGF transforming growth factor, TNF tumour necrosis factor.

development of new vaccines and the testing of new antiviral drugs, it is important to consider other steps that can be taken to support the immune system. This article will describe the influence of ageing, frailty, obesity, micronutrients and the gut microbiota on the human immune system and discuss this in the contexts of SARS-CoV-2 infection and COVID-19.

\section{An overview of the role and organisation of the immune system}

The primary role of the immune system is to protect the individual against pathogenic organisms including bacteria, viruses, fungi and parasites. So that it can provide effective protection against the wide array of threatening organisms, the human immune system has evolved to include many different cell types, many communicating molecules and multiple functional responses (Fig. 1). The immune system has four general actions. Firstly, it acts as a barrier keeping microbes from entering the body. Secondly, the immune system acts to recognise microbes and to identify whether they are harmful or not. Thirdly, the immune system acts to eliminate those microbes identified as being harmful; this involves the destructive actions of various types of immune cell. Fourthly, the immune response generates immunological memory, so that if there is re-exposure to the harmful microbe, the immune response is more rapid and stronger than it was for the original response. These complex and sophisticated actions can be achieved because the human immune system is comprised of many cell types (Fig. 1), each with their own individual functional capabilities. These different cell types interact with one another as part of the immune response to assure effective protection of the host from pathogens. The immune system may be classified in different ways, most commonly into innate (or natural) and acquired (or adaptive) immunity (Fig. 1). Innate and acquired immunity are linked and how this is achieved to provide anti-viral immunity is summarised in Fig. 2 [1].

\section{Factors affecting the immune response}

It is obvious that effective defence against pathogenic organisms requires a well-functioning immune system. Consequently, individuals with weakened immune systems are at increased risk of becoming infected and of infections being more serious, even fatal. Figure 3 highlights many of the factors that influence the immune response. These include some unmodifiable factors such as genetics, stage of 


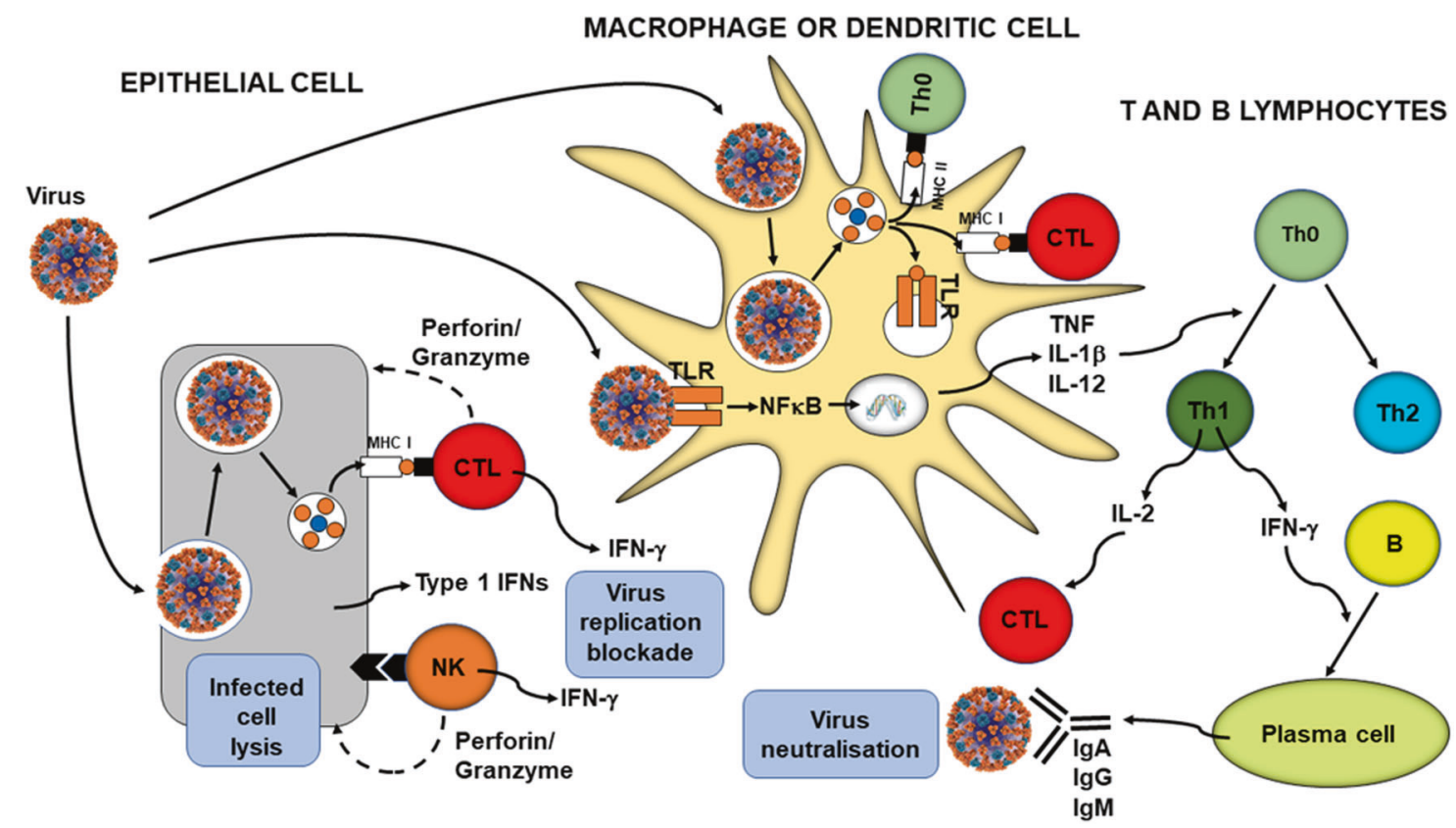

Fig. 2 Overview of anti-viral immunity. B B-cell, CTL cytotoxic Tcell, IFN interferon, Ig immunoglobulin, IL interleukin, MHC major histocompatibility class, NFKB nuclear factor kappa-light-chain- enhancer of activated B cells, NK natural killer cell, Th helper Tcell, TLR toll-like receptor, TNF tumour necrosis factor. Taken from ref. [1].
Fig. 3 Factors that influence the immune response. Note that the listing is not exclusive.

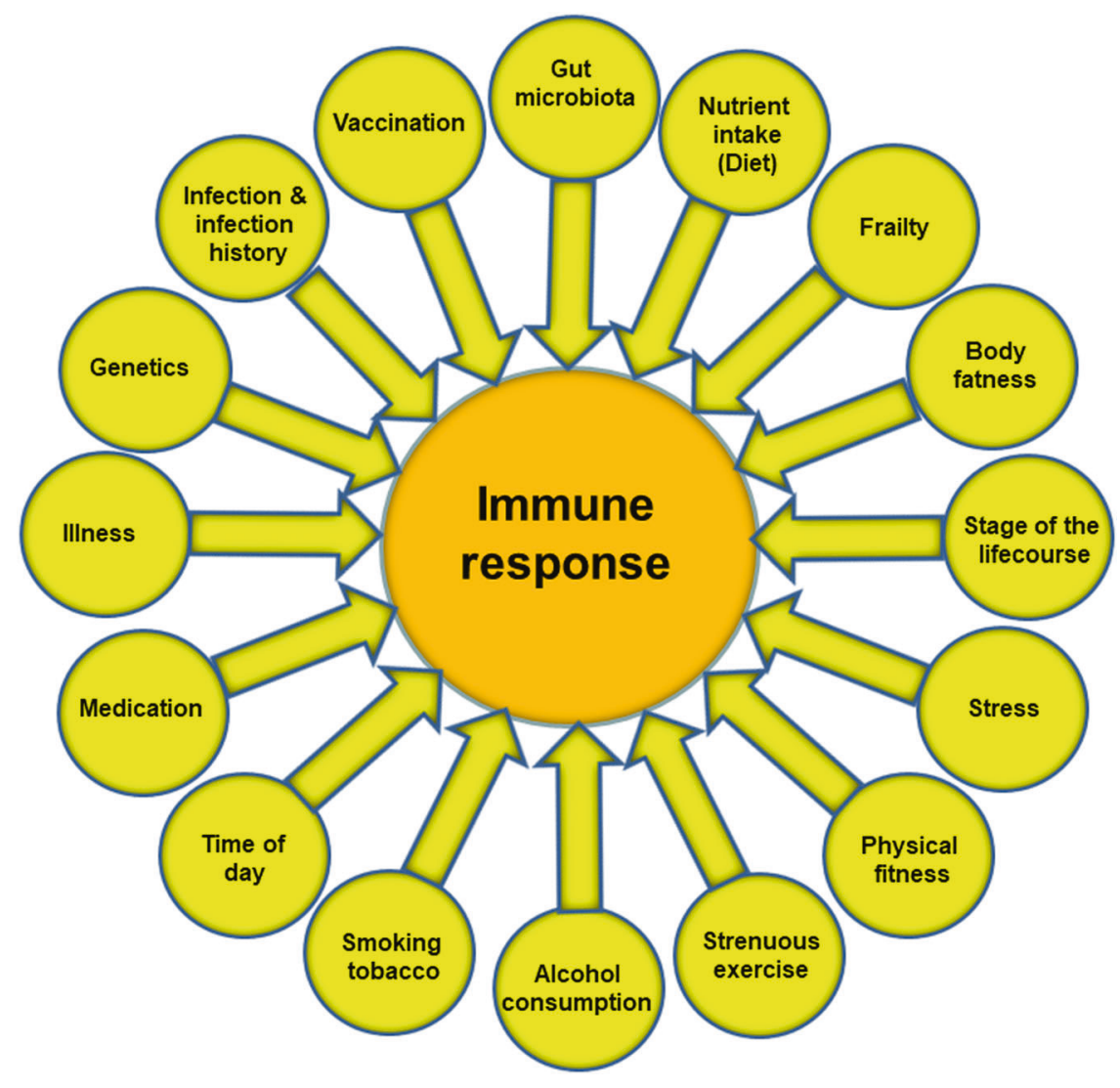

the life course (e.g. pregnancy, infancy and old age) and time of day, but many modifiable factors also influence the immune response. These include stress, physical fitness, frailty, body fatness and diet. Early in the SARS-CoV-2 pandemic it became clear that older people, particularly those who were frail, and that those living with obesity had 
higher susceptibility to more serious illness and mortality from COVID-19 than did younger people and those who were of healthy weight.

\section{The effect of ageing and frailty on immunity and susceptibility to infection}

Immune competence can be diminished with ageing, a process called immunosenescence [2,3]. One contributor to immunosenescence is likely to be the decreased output of immune cells from bone marrow, the site of origin of all immune cells, with increasing age. In addition, involution of the thymus with age decreases output of naive $\mathrm{T}$ cells, resulting in reduced capacity to respond to new antigens. In addition to altered numbers of immune cells in the circulation, their function is often impaired. For example, neutrophils show impaired phagocytosis, respiratory burst and bacterial killing. Natural killer cells have impaired cytotoxicity towards virally-infected and tumour cells. Dendritic cells have impaired responsiveness to immune signals. $\mathrm{T}$ cells have reduced ability to proliferate and to produce important cytokines like interleukin- 2 and interferon- $\gamma$. Cytotoxic T-cell activity is reduced and antibody production by B cells is altered. Hence, older people can show a broad range of immune impairments, making them more susceptible to infections [4], including respiratory illnesses caused by viruses. Immunosenescence also impairs responses to vaccination, including to the seasonal influenza vaccine $[5,6]$. Poor nutritional intake may contribute to age-related immune decline: immune decline is less in older people with better micronutrient intake or status [7]. Furthermore, amongst older people, undernutrition promotes immune decline [8] and frailty results in significant immune impairments. For example Yao et al. [9] reported that responses to all three strains within a seasonal influenza vaccine (responses measured as anti-vaccine antibody titres) were much lower in frail compared with non-frail older (72-95 years of age) people; responses of the pre-frail were intermediate. During a post-vaccination follow-up period, $50 \%$ of the frail older people developed influenza-like illness and $30 \%$ developed confirmed influenza; figures in the non-frail group were $10 \%$ and $5 \%$, respectively, and again the pre-frail were intermediate between the frail and nonfrail groups [9]. In a recent study, seroconversion of more frail older people to the four strains of a quadrivalent seasonal influenza vaccine was $8,5,0$ and $8 \%$ while seroconversion in less frail older people was $23,21,23$ and $26 \%$ [10]. That these immune impairments are of clinical significance comes from observations that less wellnourished hospitalised older people had a greater risk of infections than those who were better nourished [11, 12]. Thus, there is a link between immunosenescence and increased susceptibility to, and severity of, infections. Immunosenescence may be one factor that predisposes older people to more severe COVID-19. A number of studies also report a link between frailty and poorer outcome from COVID-19 (see ref. [13]). Ageing is also linked to an increase in blood concentrations of many inflammatory mediators, a situation termed inflammageing [14]. This state is considered to contribute to an increased risk of chronic conditions of ageing and may predispose to mounting an excessive inflammatory response when infected. Thus, older people, and again particularly those who are frail, may be pre-disposed to mounting an uncontrolled inflammatory response, sometimes termed a 'cytokine storm', that has been implicated in poor outcome from COVID-19. In summary, older people can show impaired immune responses, predisposing them to infection, and a proneness for uncontrolled inflammation, predisposing them to adverse consequences of being infected, and both these situations appear to be worse in those who are frail.

\section{The effect of obesity on immunity and susceptibility to infection}

Immune competence can be diminished with obesity [15], with impairments of the activity of helper $\mathrm{T}$ cells, cytotoxic $\mathrm{T}$ cells, $\mathrm{B}$ cells and natural killer cells, and reduced antibody and interferon- $\gamma$ production. This means that, compared with healthy weight individuals, those living with obesity have increased susceptibility to a range of bacterial, viral and fungal infections [16], and poorer responses to vaccination [17]. The impact of obesity has been well explored in relation to influenza infection and vaccination against influenza. During the 2009 H1N1 influenza A virus pandemic, those living with obesity showed delayed and weakened anti-viral responses to infection and showed poorer recovery from disease compared with healthy weight individuals [18]. Animal studies and case studies in humans show that obesity is associated with prolonged shedding of influenza virus, indicating an impairment in viral control and killing; obesity is also linked with the emergence of virulent minor variants [18]. Vaccines may also be less effective in those living with obesity: compared with healthy weight individuals, vaccinated individuals living with obesity have twice the risk of influenza or influenza-like illness, indicating poorer protection from vaccination in those with obesity [19]. Sheridan et al. [20] investigated the responses of immune cells taken from the blood of healthy weight individuals and those with overweight or obesity to the influenza vaccine in vitro. Exposure of the blood immune cells to the vaccine increased the number of activated cytotoxic $\mathrm{T}$ cells, the number of granzyme expressing cytotoxic 
$\mathrm{T}$ cells and the number of interferon- $\gamma$ producing cytotoxic T cells, all key components of anti-viral immunity (Fig. 2). However, the responses of cells from individuals with obesity were reduced by $40 \%$, almost $60 \%$ and $65 \%$, respectively. Cells from individuals with overweight showed responses intermediate between those from healthy weight and those with obesity. Similar findings for the response of blood cells to the pandemic H1N1 influenza A virus were reported by Paich et al. [21]. Thus, obesity is linked to multiple immune impairments, including to responses involved in protection against viruses. Obesity is also associated with an increase in blood concentrations of many inflammatory mediators, a state of chronic low-grade inflammation [22]. This state is considered to contribute to an increased risk of chronic conditions associated with obesity and may predispose to mounting an excessive inflammatory response when infected. It is now well described that those living with obesity are more susceptible to severe COVID-19 and to mortality from COVID-19 than healthy weight adults. For example, a recently published systematic review and meta-analysis of 22 studies from seven countries in North America, Europe, and Asia, reported that obesity is associated with an increased likelihood of presenting with more severe COVID-19 symptoms (odds ratio 3.03; four studies), requiring hospitalisation (adds ratio 1.68; four studies), being admitted to an intensive care unit (odds ratio 1.35; nine studies), undergoing invasive mechanical ventilation (odds ratio 1.76; seven studies) and developing acute respiratory distress syndrome (odds ratio 2.89; two studies) compared to patients without obesity [23]. In summary, those living with obesity can show impaired immune responses, predisposing them to infection, and a proneness towards uncontrolled inflammation, predisposing them to adverse consequences of being infected.

\section{The role of micronutrients in supporting the immune response}

Nutrition plays multiple roles in supporting the immune system. The diet provides:

- Fuels for the immune system to function.

- Building blocks for the generation of RNA and DNA and for the production of proteins (antibodies, cytokines, receptors, acute phase proteins etc.) and new cells.

- Specific substrates for the production of immune-active metabolites (e.g. arginine as a substrate for nitric oxide).

- Regulators of immune cell metabolism (e.g. vitamin A, zinc).

- Nutrients with specific antibacterial or anti-viral functions (e.g. vitamin D, zinc).

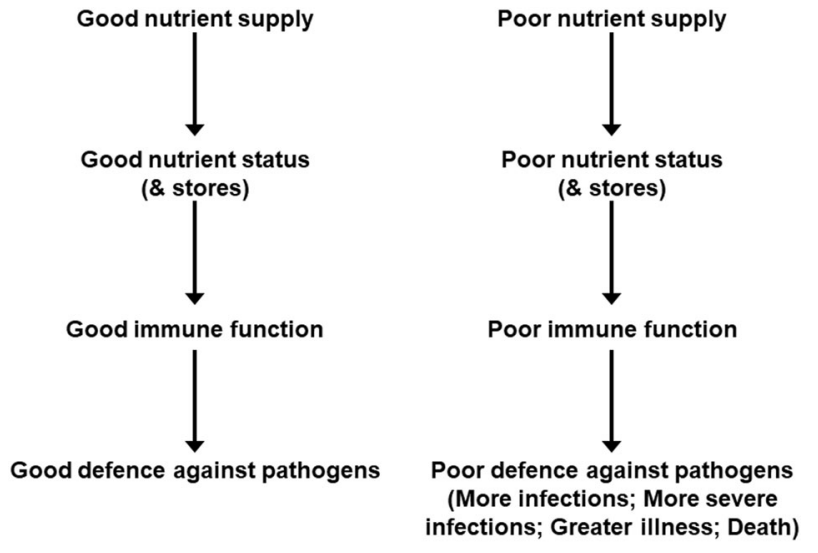

Fig. 4 Relationships between good and poor nutrition, immunity and infection.

- Regulators that protect the host from oxidative and inflammatory stress (e.g. vitamin C, vitamin E, zinc, selenium, long-chain omega-3 fatty acids and many plant polyphenols).

- Substrates for the intestinal microbiota which in turn modulates the immune system (see next section).

Poor nutrition may not provide sufficient amounts of the nutrients needed by the immune system to function well. This would be associated with increased susceptibility to infection and inability to control the effects of being infected (Fig. 4). In this regard the role of micronutrients in supporting the immune system has been widely studied, as reviewed elsewhere [1, 24-26]. Multiple micronutrients play vital roles in supporting the immune response (Table 1). The roles of vitamins A, C and D and zinc, copper and iron are well explored, but B vitamins, vitamin $\mathrm{E}$, vitamin $\mathrm{K}$, selenium, magnesium and others all have roles. Deficiencies of several of these micronutrients impair many aspects of both innate and acquired immunity and increase susceptibility to infections [1, 24]. The immune impairments can be reversed by repletion and this reduces susceptibility to infection. There has been discussion around many micronutrients and anti-viral immunity in the context of infection with SARS-CoV-2 and COVID-19 and there have been numerous publications on this topic since the start of the SARS-CoV-2 pandemic.

Vitamin D has pleiotropic actions within the immune system but does support the activity of several cell types [27]. Furthermore, some immune cells (dendritic cells, macrophages) can produce the active form of vitamin $\mathrm{D}$ suggesting it is important to immunity. Vitamin D also promotes the production of antimicrobial proteins such as cathelicidin. Vitamin D deficiency impairs the response to the seasonal influenza vaccine [28] and meta-analyses of randomised controlled trials of vitamin D supplementation report reduced incidence of respiratory tract infections [29]. 


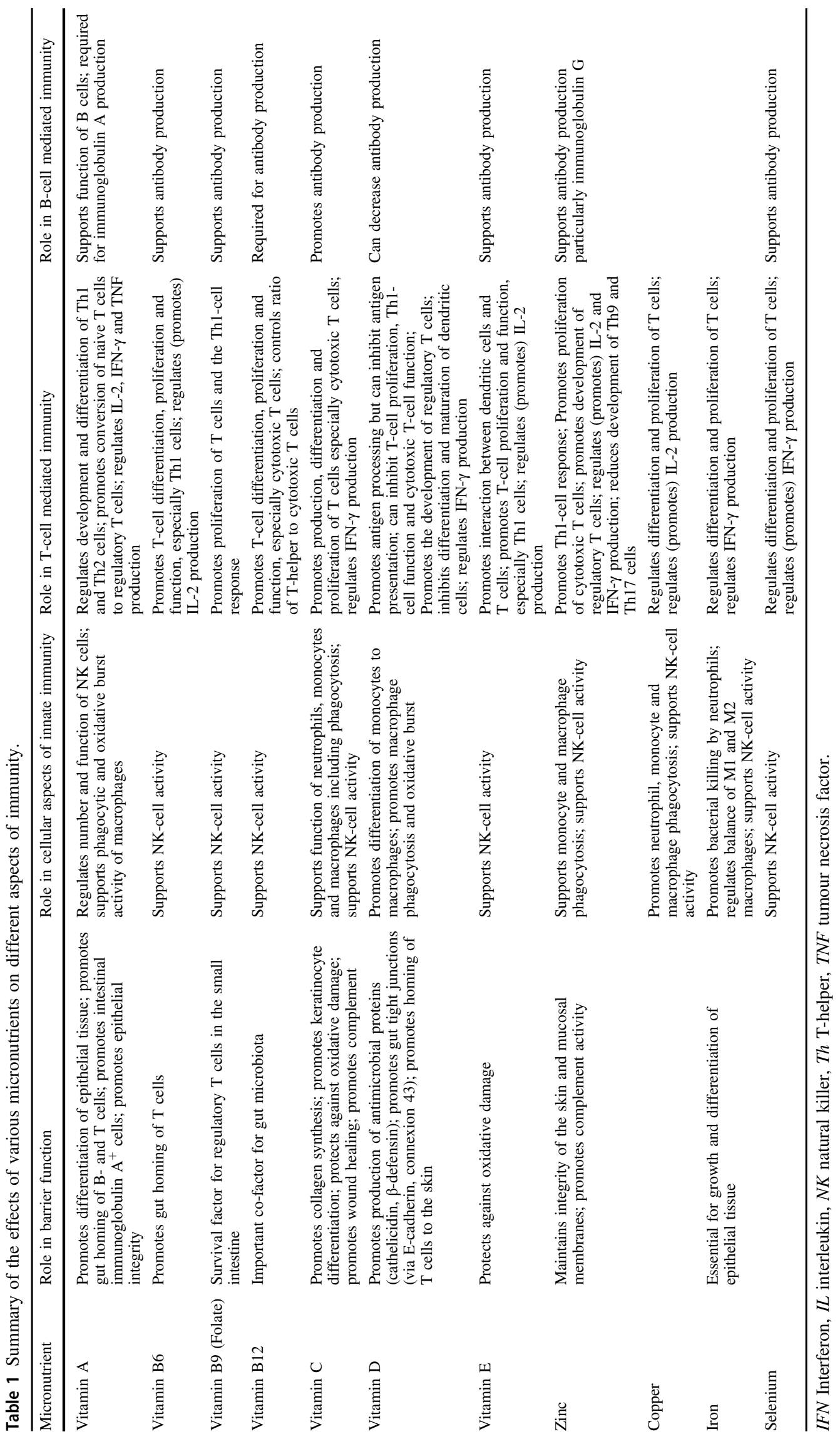


Multiple studies report an association between low vitamin D status and increased susceptibility to, and severity of, COVID-19. A large Israeli study reported that low vitamin D status increased the risk of infection with SARS-CoV-2 and increased risk of hospitalisation with COVID-19 [30]. Meta-analyses report that vitamin D deficiency increases risk of severe COVID-19, hospitalisation with COVID-19 and mortality from COVID-19 [31]. A large study using data from the UK Biobank reported that using vitamin D supplements decreased risk of a positive test for SARSCoV-2 after controlling for multiple confounders [32]. A study in an Italian residential care home reported that a bolus of vitamin D reduced mortality from COVID-19 [33]. Vitamin D supplementation in patients hospitalised with COVID-19 is reported to reduce COVID-19 severity (need for intensive care unit admission [34]; need for intensive care unit admission or mortality [35]; mortality [36]).

Zinc supports the activity of many cells of the immune system [37], helps to control oxidative stress and inflammation and has specific anti-viral actions [38] including inhibiting the replication of coronaviruses [39]. Zinc supplementation improves some markers of immunity especially in older people or those with low zinc intake [40], improves vaccination responses [41] and meta-analyses of randomised controlled trials of zinc supplementation report reduced incidence of diarrhoeal and respiratory tract infections (see ref. [1] for references). Multiple studies report an association between low zinc status and increased susceptibility to and severity of COVID-19 (e.g. [42]). Zinc supplementation in patients hospitalised with COVID-19 is reported to reduce risk of poor outcome including mortality $[43,44]$.

In contrast to the large literature on vitamin $\mathrm{D}$ and zinc that has emerged during the pandemic, there has been less research on selenium. Nevertheless, selenium may have important roles in supporting the immune system in general and in promoting anti-viral immunity in particular [45]. Selenium supports the activity of many cells of the immune system and helps to control oxidative stress and inflammation. Extensive research in mice has shown that selenium deficiency impairs immune responses, increases susceptibility to viral infection, permits viruses (including influenza viruses) to mutate, and allows normally weak viruses to become more virulent. Selenium supplementation improves some markers of immunity especially in older people or those with low selenium intake; for example a supplementation study conducted in UK adults with marginal selenium status showed that selenium improved ex vivo anti-viral immune responses, promoted viral clearance and decreased viral mutation [46]. Several studies report an association between low selenium status and increased susceptibility to and severity of COVID-19 (e.g. $[42,47])$.
Taken together, the existing evidence indicates that multiple micronutrients play vital roles in supporting all aspects of the immune response and therefore that their intake and status need to be considered in the context of susceptibility to SARS-CoV-2 infection and COVID-19 severity. Roles of specific nutrients including vitamin $\mathrm{D}$ and zinc in anti-viral immunity seem to be important and the ability of selenium to prevent viral mutation is intriguing in the context of the emergence of SARS-CoV-2 variants. Furthermore, low intakes of several micronutrients impair vaccination responses and so must be considered in the context of the current and future COVID-19 vaccination programmes; this is likely to be particularly important in the elderly [48] but also in other groups who are more likely to have low intakes or status of one or more micronutrients. Although micronutrients are provided as part of a diverse, plant-based diet (see ref. [1]) there is a question about whether sufficient amounts of some of the key immuneactive micronutrients (vitamin $\mathrm{D}$, vitamin $\mathrm{C}$, vitamin $\mathrm{E}$, zinc and selenium) can be obtained from the diet or whether supplements are necessary to provide the relevant intakes of these micronutrients [26].

\section{The importance of the gut microbiota}

Commensal bacteria within the gastrointestinal tract play a role in host immune defence by creating a barrier against colonisation by pathogens and through the production of lactic acid and antimicrobial proteins which can directly inhibit the growth of pathogens. Commensal organisms also interact with the host's gut epithelium and gut-associated immune tissues. These communications with the host occur through chemicals released from the bacteria or through direct cell-to-cell contact. As a result of such actions, it is proposed that probiotic organisms, particularly some lactobacilli and bifidobacteria, can be used to support host immunity. In fact, a large number of studies have examined the influence of various probiotic organisms, either alone or in combination, on immune function and infection in human subjects. Some probiotic organisms appear to enhance innate immunity (particularly phagocytosis and natural killer cell activity) but they seem to have a less pronounced effect on acquired immunity [49]. Nevertheless, studies show improved vaccination responses in individuals taking probiotics, as reviewed elsewhere [50]. Systematic reviews and meta-analyses confirm that probiotics (or prebiotics) enhance the antibody response to seasonal influenza vaccination in adults [51, 52]. The immune effects observed suggest that probiotic organisms could protect against infections. Recent systematic reviews and meta-analyses report that some probiotics can reduce the risk or duration of diarrhoea, including antibiotic-associated diarrhoea and 


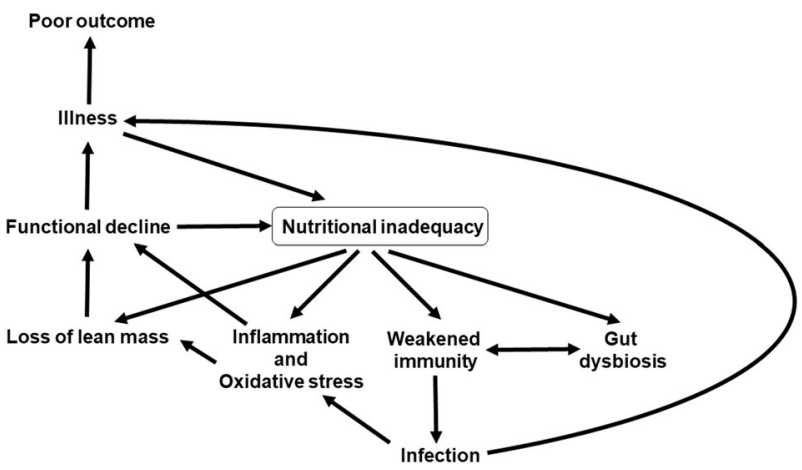

Fig. 5 Factors linking nutritional inadequacy with infection and poor outcome from infection.

Clostridium difficile-associated diarrhoea (see ref. [1] for references). Effects of probiotics on gastrointestinal infection may not be a surprise, but probiotics may also be protective against respiratory infection. Studies in mice have reported that depletion or absence of gut microbiota leads to impaired immune responses and worsen outcomes following bacterial or viral respiratory infection. Studies of probiotics, particularly lactobacilli and bifidobacterial, provide some evidence for reduced incidence, and improved outcomes, of respiratory infections in humans (see ref. [1] for references). The totality of the evidence demonstrating that probiotics (especially lactobacilli and bifidobacteria) may improve immune function, enhance the response to seasonal influenza vaccination (which mimics a viral infection), reduce the incidence of respiratory infections, including those caused by viruses, and improve outcomes in those with respiratory infections would favour the use of these organisms as a strategy to reduce the risk and severity of viral respiratory infections, including SARS-CoV-2. In this context, intestinal dysbiosis, with low numbers of lactobacilli and bifidobacteria, has been reported in patients with COVID-19 [53, 54]. D'Ettore et al. [55] treated patients with COVID-19 with a cocktail of drugs plus antibiotics or the same plus oral probiotics (five lactobacilli plus two bifidobacteria plus Streptococcus thermophilus): they found better resolution of diarrhoea and of other disease symptoms including respiratory disease in the group receiving probiotics.

\section{Discussion and conclusions}

Nutrition is one of multiple factors that determines the immune response (Fig. 3) and good nutrition is important in supporting the immune response (Fig. 4). Immunity can be impaired in older people, particularly those who are frail, in those living with obesity, in those who are malnourished and in those with low intakes of micronutrients. These immune impairments associated with nutritional inadequacy increase susceptibility to infection and permit infections to become more severe, even fatal (Fig. 5). Nutritional inadequacy also allows dysregulated inflammation and oxidative stress contributing to frailty and to poor outcome from infection (Fig. 5). The adverse impact of poor nutrition on the immune system, including its inflammatory component, may be one of the explanations for the higher risk of more severe outcomes from infection with SARS-CoV-2 seen in older people and in those living with obesity. The role of good nutrition in promoting a diverse gut microbiota, which in turn supports the immune system should not be overlooked and it is important to note that the gut microbiota is also affected by ageing and by obesity (see [1] for references). The importance of good nutrition in supporting the immune response also applies to assuring good responses to vaccination. Thus, attention should be focussed on addressing the current nutritional inadequacies (frailty, obesity, general undernutrition, micronutrient insufficiency or deficiency) that are widespread in the population in order to better support the immune response. This is the major lesson from the study of nutrition and immunity that is relevant for the battle with SARS-CoV-2 and the disease it causes, COVID-19, and for ensuring the population is better prepared for future pandemics.

\section{Compliance with ethical standards}

Conflict of interest PCC has research funding from Bayer Consumer Care and acts as an advisor/consultant to BASF AS, DSM, Cargill, Smartfish, Nutrileads, Bayer Consumer Care and GSK Consumer Healthcare.

Publisher's note Springer Nature remains neutral with regard to jurisdictional claims in published maps and institutional affiliations.

Open Access This article is licensed under a Creative Commons Attribution 4.0 International License, which permits use, sharing, adaptation, distribution and reproduction in any medium or format, as long as you give appropriate credit to the original author(s) and the source, provide a link to the Creative Commons license, and indicate if changes were made. The images or other third party material in this article are included in the article's Creative Commons license, unless indicated otherwise in a credit line to the material. If material is not included in the article's Creative Commons license and your intended use is not permitted by statutory regulation or exceeds the permitted use, you will need to obtain permission directly from the copyright holder. To view a copy of this license, visit http://creativecommons. org/licenses/by/4.0/.

\section{References}

1. Calder PC. Nutrition, immunity and COVID-19. BMJ Nutr Prev Health. 2020;3:e00085. https://doi.org/10.1136/bmjnph-2020000085.

2. Pawelec G, Larbi A, Derhovanessian E. Senescence of the human immune system. J Comp Pathol. 2010;142:S39-44. https://doi. org/10.1016/j.jcpa.2009.09.005. 
3. Agarwal S, Busse PJ. Innate and adaptive immunosenescence. Ann Allergy Asthma Immunol. 2010;104:183-90. https://doi.org/ 10.1016/j.anai.2009.11.009.

4. Yoshikawa TT. Epidemiology and unique aspects of aging and infectious diseases. Clin Infect Dis. 2000;30:931-3. https://doi. org/10.1086/313792.

5. Goodwin K, Viboud C, Simonsen L. Antibody response to influenza vaccination in the elderly: a quantitative review. Vaccine. 2006;24:1159-69. https://doi.org/10.1016/j.vaccine.2005.08.105.

6. Pera A, Campos C, López N, Hassouneh F, Alonso C, Tarazona $\mathrm{R}$, et al. Immunosenescence: implications for response to infection and vaccination in older people. Maturitas. 2015;82:50-5. https:// doi.org/10.1016/j.maturitas.2015.05.004.

7. Lesourd B. Nutritional factors and immunological ageing. Proc Nutr Soc. 2006;65:319-25. https://doi.org/10.1079/pns2006507.

8. Lesourd B. Nutrition: a major factor influencing immunity in the elderly. J Nutr Health Aging. 2004;8:28-37.

9. Yao X, Hamilton RG, Weng N-P, Xue Q-L, Bream JH, Li H, et al. Frailty is associated with impairment of vaccine-induced antibody response and increase in post-vaccination influenza infection in community-dwelling older adults. Vaccine. 2011;39:5015-21. https://doi.org/10.1016/j.vaccine.2011.04.077.

10. Castro-Herrera VM, Fisk HL, Wootton M, Lown M, Owen-Jones E, Lau M, et al. Combination of the probiotics Lacticaseibacillus rhamnosus $\mathrm{GG}$ and Bifidobacterium animalis subsp. lactis, BB-12 has limited effect on biomarkers of immunity and inflammation in older people resident in care homes: results from the Probiotics to Reduce Infections iN CarE home reSidentS Randomized, Controlled Trial. Front Immunol. 2021;12:643321. https://doi.org/10. 3389/fimmu.2021.643321.

11. Schneider SM, Veyres P, Pivot X, Soummer AM, Jambou P, Filippi $J$, et al. Malnutrition is an independent factor associated with nosocomial infections. Brit J Nutr. 2004;92:105-11. https:// doi.org/10.1079/BJN20041152.

12. Paillaud E, Herbaud S, Caillet P, Lejonc J-L, Campillo B, Bories $\mathrm{P}-\mathrm{N}$. Relations between undernutrition and nosocomial infections in elderly patients. Age Ageing. 2005;34:619-25. https://doi.org/ 10.1093/ageing/afi197.

13. Maltese G, Corsonello A, Di Rosa M, Soraci L, Vitale C, Corica F, et al. Frailty and COVID-19: a systematic scoping review. J Clin Med. 2020;9:2106. https://doi.org/10.3390/jcm9072106.

14. Calder PC, Bosco N, Bourdet-Sicard R, Capuron L, Delzenne N, Doré $\mathrm{J}$, et al. Health relevance of the modification of low grade inflammation in ageing (inflammageing) and the role of nutrition. Ageing Res Rev. 2017;40:95-119. https://doi.org/10.1016/j.arr. 2017.09.001.

15. Milner JJ, Beck MA. The impact of obesity on the immune response to infection. Proc Nutr Soc. 2012;71:298-306. https:// doi.org/10.1017/S0029665112000158.

16. Huttunen R, Syrjänen J. Obesity and the risk and outcome of infection. Int J Obes. 2013;37:333-40. https://doi.org/10.1038/ijo. 2012.62.

17. Frasca D, Blomberg BB. The impact of obesity and metabolic syndrome on vaccination success. Interdiscip Top Gerontol Geriatr. 2020;43:86-97.

18. Honce R, Schultz- Cherry S. Impact of obesity on influenza A virus pathogenesis, immune response, and evolution. Front Immunol. 2019;10:1071. https://doi.org/10.1159/000504440.

19. Green WD, Beck MA. Obesity impairs the adaptive immune response to influenza virus. Ann Am Thorac Soc. 2017;14: S406-9. https://doi.org/10.1513/AnnalsATS.201706-447AW.

20. Sheridan PA, Paich HA, Handy J, Karlsson EA, Hudgens MG, Sammon AB, et al. Obesity is associated with impaired immune response to influenza vaccination in humans. Int $\mathrm{J}$ Obes. 2012;36:1072-7. https://doi.org/10.1038/ijo.2011.208.
21. Paich HA, Sheridan PA, Handy J, Karlsson EA, Schultz-Cherry S, Hudgens MG, et al. Overweight and obese adult humans have a defective cellular immune response to pandemic H1N1 influenza A virus. Obesity. 2013;21:2377-86. https://doi.org/10.1002/oby. 20383.

22. Calder PC, Ahluwalia N, Brouns F, Buetler T, Clement K, Cunningham $\mathrm{K}$, et al. Dietary factors and low- grade inflammation in relation to overweight and obesity. Br J Nutr. 2011;106:S5-78. https://doi.org/10.1017/S0007114511005460.

23. Zhang X, Lewis AM, Moley JR, Brestoff JR. A systematic review and meta-analysis of obesity and COVID-19 outcomes. Sci Rep. 2021;11:7193. https://doi.org/10.1038/s41598-021-86694-1.

24. Gombart AF, Pierre A, Maggini S. A review of micronutrients and the immune System-Working in harmony to reduce the risk of infection. Nutrients. 2020;12:E236. https://doi.org/10.3390/ nu12010236.

25. Maggini S, Pierre A, Calder PC. Immune function and micronutrient requirements change over the life course. Nutrients. 2018;10:1531. https://doi.org/10.3390/nu10101531.

26. Calder PC, Carr AC, Gombart AF, Eggersdorfer M. Optimal nutritional status for a well-functioning immune system is an important factor to protect against viral infections. Nutrients. 2020;12:1181. https://doi.org/10.3390/nu12041181.

27. Prietl B, Treiber G, Pieber T, Amrein K. Vitamin D and immune function. Nutrients. 2013;5:2502-21. https://doi.org/10.3390/ nu5072502.

28. Lee M-D, Lin C-H, Lei W-T, Chang H-Y, Lee H-C, Yeung C-Y, et al. Does vitamin D deficiency affect the immunogenic responses to influenza vaccination? A systematic review and meta- analysis. Nutrients. 2018;10:409. https://doi.org/10.3390/ nu10040409.

29. Martineau AR, Jolliffe DA, Hooper RL, Greenberg L, Aloia JF, Bergman P, et al. Vitamin D supplementation to prevent acute respiratory tract infections: systematic review and meta- analysis of individual participant data. BMJ. 2017;356:i6583. https://doi. org/10.1136/bmj.i6583.

30. Merzon E, Tworowski D, Gorohovski A, Vinker S, Golan Cohen A, Green I, et al. Low plasma $25(\mathrm{OH})$ vitamin D level is associated with increased risk of COVID-19 infection: an Israeli population-based study. FEBS J. 2020;287:3693-702. https://doi. org/10.1111/febs.15495.

31. Pereira M, Dantas Damascena A, Galvão Azevedo LM, de Almeida Oliveira T, da Mota Santana J. Vitamin D deficiency aggravates COVID-19: systematic review and meta-analysis. Crit Rev Food Sci Nutr. https://doi.org/10.1080/10408398.2020. 1841090. 2021. In press.

32. Ma H, Zhou T, Heianza Y, Qi L. Habitual use of vitamin D supplements and risk of coronavirus disease 2019 (COVID-19) infection: a prospective study in UK Biobank. Am J Clin Nutr. 2021;113:1275-81. https://doi.org/10.1093/ajen/nqaa381.

33. Cangiano B, Fatti LM, Danesi L, Gazzano G, Croci M, Vitale G, et al. Mortality in an Italian nursing home during COVID-19 pandemic: correlation with gender, age, ADL, vitamin D supplementation, and limitations of the diagnostic tests. Aging. 2020;12:24522-34. https://doi.org/10.18632/aging.202307.

34. Entrenas Castillo M, Entrenas Costa LM, Vaquero Barrios JM, Alcalá Díaz JF, López Miranda J, Bouillon R, et al. Effect of calcifediol treatment and best available therapy versus best available therapy on intensive care unit admission and mortality among patients hospitalized for COVID-19: a pilot randomized clinical study. J Steroid Biochem Mol Biol. 2020;203:105751. https://doi.org/10.1016/j.jsbmb.2020.105751.

35. Giannini S, Passeri G, Tripepi G, Sella S, Fusaro M, Arcidiacono $\mathrm{G}$, et al. Effectiveness of in-hospital cholecalciferol use on clinical outcomes in comorbid COVID-19 patients: a hypothesis- 
generating study. Nutrients. 2021;13:219. https://doi.org/10.3390/ nu13010219.

36. Ling SF, Broad E, Murphy R, Pappachan JM, Pardesi-Newton S, Kong MF, et al. High-dose cholecalciferol booster therapy is associated with a reduced risk of mortality in patients with COVID-19: a cross-sectional multi-centre observational study. Nutrients. 2020;12:3799. https://doi.org/10.3390/nu12123799.

37. Wessels I, Maywald M, Rink L. Zinc as a gatekeeper of immune function. Nutrients. 2017;9:1286. https://doi.org/10.3390/nu9121286.

38. Read SA, Obeid S, Ahlenstiel C, Ahlenstiel G. The role of zinc in antiviral immunity. Adv Nutr. 2019;10:696-710. https://doi.org/ 10.1093/advances/nmz013.

39. te Velthuis AJW, van den Worm SHE, Sims AC, Baric RS, Snijder EJ, van Hemert MJ. $\mathrm{Zn}^{2+}$ inhibits coronavirus and arterivirus RNA polymerase activity in vitro and zinc ionophores block the replication of these viruses in cell culture. PLoS Pathol. 2010;6:e1001176. https://doi.org/10.1371/journal.ppat.1001176.

40. Barnett JB, Dao MC, Hamer DH, Kandel R, Brandeis G, Wu D, et al. Effect of zinc supplementation on serum zinc concentration and $\mathrm{T}$ cell proliferation in nursing home elderly: a randomized, double-blind, placebo-controlled trial. Am J Clin Nutr. 2016;103:942-51. https://doi.org/10.3945/ajen.115.115188.

41. Karlsen TH, Sommerfelt H, Klomstad S, Kragh Andersen P, Strand TA, Ulvik RJ, et al. Intestinal and systemic immune responses to an oral cholera toxoid B subunit whole-cell vaccine administered during zinc supplementation. Infect Immun. 2003;71:3909-113. https://doi.org/10.1128/iai.71.7.3909-3913.2003.

42. Heller RA, Sun Q, Hackler J, Seelig J, Seibert L, Cherkezov A, et al. Prediction of survival odds in COVID-19 by zinc, age and selenoprotein $\mathrm{P}$ as composite biomarker. Redox Biol. 2021;38:101764. https://doi.org/10.1016/j.redox.2020.101764.

43. Carlucci PM, Ahuja T, Petrilli C, Rajagopalan H, Jones S, Rahimian J. Zinc sulfate in combination with a zinc ionophore may improve outcomes in hospitalized COVID-19 patients. J Med Microbiol. 2020;69:1228-34. https://doi.org/10.1099/jmm.0.001250.

44. Frontera JA, Rahimian JO, Yaghi S, Liu M, Lewis A, de Havenon A, et al. Treatment with zinc is associated with reduced in-hospital mortality among COVID-19 patients: a multi-center cohort study. Res Sq. 2020;3:rs.3.rs-94509. https://doi.org/10.21203/rs.3.rs94509/v1. Preprint.

45. Avery J, Hoffmann P. Selenium, selenoproteins, and immunity. Nutrients. 2018;10:1203. https://doi.org/10.3390/nu10091203.
46. Broome CS, McArdle F, Kyle JAM, Andrews F, Lowe NM, Hart $\mathrm{CA}$, et al. An increase in selenium intake improves immune function and poliovirus handling in adults with marginal selenium status. Am J Clin Nutr. 2004;80:154-62. https://doi.org/10.1093/ajcn/80.1.154.

47. Moghaddam A, Heller RA, Sun Q, Seelig J, Cherkezov A, Seibert $\mathrm{L}$, et al. Selenium deficiency is associated with mortality risk from COVID-19. Nutrients. 2020;12:2098. https://doi.org/10.3390/ nu12072098.

48. Rayman MP, Calder PC. Optimising COVID-19 vaccine efficacy by ensuring nutritional adequacy. Brit J Nutr. https://doi.org/10. 1017/S0007114521000386. 2021. In press.

49. Lomax AL, Calder PC. Probiotics, immune function, infection and inflammation: a review of the evidence from studies conducted in humans. Curr Pharm Des. 2009;15:1428-518. https:// doi.org/10.2174/138161209788168155.

50. Maidens C, Childs C, Przemska A, Bin Dayel I, Yaqoob P. Modulation of vaccine response by concomitant probiotic administration. Brit J Clin Pharmacol. 2013;75:663-70. https:// doi.org/10.1111/j.1365-2125.2012.04404.X.

51. Lei W-T, Shih P-C, Liu S-J, Lin C-Y, Yeh T-L. Effect of probiotics and prebiotics on immune response to influenza vaccination in adults: a systematic review and meta- analysis of randomized controlled trials. Nutrients. 2017;9:1175. https://doi. org/10.3390/nu9111175.

52. Yeh T-L, Shih P-C, Liu S-J, Lin C-H, Liu J-M, Lei W-T, et al. The influence of prebiotic or probiotic supplementation on antibody titers after influenza vaccination: a systematic review and meta- analysis of randomized controlled trials. Drug Des Devel Ther. 2018;12:217-30. https://doi.org/10.2147/DDDT.S155110.

53. Xu K, Cai H, Shen Y, Ni Q, Chen Y, Hu S, et al. Management of corona virus disease-19 (COVID-19): the Zhejiang experience. [Article in Chinese]. Zhejiang Da Xue Xue Bao Yi Xue Ban. 2020;49:147-57. https://doi.org/10.3785/j.issn.1008-9292.2020.02.02.

54. Zuo T, Zhang F, Lui GCY, Yeoh YK, Li AYL, Zhan H, et al. Alterations in gut microbiota of patients with COVID-19 during time of hospitalization. Gastroenterol. 2020;159:944-55.e8. https://doi.org/10.1053/j.gastro.2020.05.048.

55. d'Ettorre G, Ceccarelli G, Marazzato M, Campagna G, Pinacchio $\mathrm{C}$, Alessandri $\mathrm{F}$, et al. Challenges in the management of SARSCoV2 infection: the role of oral bacteriotherapy as complementary therapeutic strategy to avoid the progression of COVID-19. Front Med. 2020;7:389. https://doi.org/10.3389/fmed.2020.00389. 